\title{
Inoculantes formulados com polímeros e bactérias endofíticas para a cultura da cana-de-açúcar
}

\author{
Marinete Flores da Silva(1), Paulo Janssen de Oliveira(2), Gustavo Ribeiro Xavier ${ }^{(3)}$, \\ Norma Gouvêa Rumjanek ${ }^{(3)}$ e Veronica Massena Reis ${ }^{(3)}$
}

(1)Universidade Federal Rural do Rio de Janeiro (UFRRJ), Departamento de Ciência do Solo, BR 465, Km 7, CEP 23890-000 Seropédica, RJ.
E-mail: marineteflores@yahoo.com.br (2)UFRRJ, Departamento de Engenharia Química. E-mail: pjansen@ufrj.br ${ }^{(3)}$ Embrapa Agrobiologia,
BR 465, Km 7, CEP 23890-000 Seropédica, RJ. E-mail: gustavo@cnpab.embrapa.br, norma@cnpab.embrapa.br, veronica@cnpab.embrapa.br

Resumo - O objetivo deste trabalho foi avaliar o efeito da utilização, em campo, de inoculantes compostos pela mistura de estirpes de bactérias diazotróficas e pelos polímeros carboximetilcelulose e amido, sobre a fixação de nitrogênio, em cana-de-açucar. O delineamento experimental foi de blocos ao acaso, em esquema fatorial $4 \times 2$, com quatro formas de fornecimento de $\mathrm{N}$ : controle absoluto, controle nitrogênio (adubação com $120 \mathrm{~kg} \mathrm{ha}^{-1} \mathrm{de} \mathrm{N}$ ), inoculante polimérico líquido (IPC 0,8), e inoculante polimérico gel (IPC 2,2); e duas variedades de cana-de-açúcar (RB72454 e RB867515), em parcelas subdivididas (três épocas de avaliação $-6,9$ e 11 meses após o plantio), com quatro repetições. Como veículo inoculante foi testada a proporção 60:40 dos polímeros carboximetilcelulose e amido, nas concentrações 0,8 e 2,2 $\mathrm{g} \mathrm{L}^{-1}$ (IPC 0,8 e IPC 2,2, respectivamente). Os parâmetros avaliados foram: a produtividade de colmos, a massa de matéria seca total e o acúmulo de nitrogênio. Os tratamentos com os inoculantes com a mistura de bactérias diazotróficas endofíticas e os polímeros promoveram aumento médio da produtividade das variedades RB72454 e RB867515 de 50 e $30 \mathrm{Mg} \mathrm{ha}^{-1}$, respectivamente, e aumento médio da massa da matéria seca da variedade RB867515 de $18 \mathrm{Mg} \mathrm{ha}^{-1}$, em comparação ao controle absoluto, aos 11 meses após a inoculação, e não diferiram significativamente do tratamento controle nitrogênio.

Termos para indexação: Saccharum officinarum, amido, bactérias diazotróficas, carboximetilcelulose.

\section{Inoculants containing polymers and endophytic bacteria for the sugarcane crop}

\begin{abstract}
The objective of this work was to evaluate the effects of field application of inoculants composed of a mixture of diazotrophic bacterial strains and of carboxymethyl cellulose and starch polymers on nitrogen fixation in sugarcane. The experimental design was in randomized blocks in a $4 \times 2$ factorial arrangement: four types of nitrogen supply - absolute control, nitrogen control fertilized with $120 \mathrm{~kg} \mathrm{~N}$ (urea) ha ${ }^{-1}$, polymeric liquid inoculant - IPC 0.8, and polymeric gel inoculant - IPC 2.2; and two sugarcane varieties (RB72454 and RB867515), with split plots (three harvest times $-6,9$ and 11 months after planting), with four replicates. As inoculant vehicles, carboxymethyl cellulose and starch polymers with a 60:40 ratio were tested at 0.8 and $2.2 \mathrm{~g} \mathrm{~L}^{-1}$ concentrations (IPC 0.8 and IPC 2.2, respectively). The evaluated parameters were stem productivity, total dry matter and nitrogen accumulation. The treatments with the inoculants containing a mixture of diazotrophic bacteria and polymers led to an average increase of 50 and $30 \mathrm{Mg} \mathrm{ha}^{-1}$ in the productivity of the varieties RB72454 and RB867515, respectively, and to an average increase of $18 \mathrm{Mg} \mathrm{ha}^{-1}$ in total dry matter of variety RB867515, in comparison to the absolute control 11 months after inoculation, with no significant difference from the nitrogen control.
\end{abstract}

Index terms: Saccharum officinarum, starch, diazotrophic bacteria, carboxymethyl cellulose.

\section{Introdução}

OBrasiléomaiorprodutormundial de cana-de-açúcar (Saccharum officinarum L.), com cerca de oito milhões de hectares de área cultivada e produção de cerca de $675 \mathrm{Mg}$ (Instituto Brasileiro de Geografia e Estatística, 2009). Essa cultura, por ter capacidade de produzir e acumular sacarose, é considerada uma das espécies da família Poaceae de maior importância econômica do mundo, com matéria-prima que permite os menores custos de produção de açúcar e álcool, pelo fato de a energia consumida no processo ser proveniente dos próprios resíduos (Brasil, 2008). 
Bactérias diazotróficas podem associar-se à cana-de-açúcar naturalmente ou podem ser inoculadas para promover efeitos benéficos. Oliveira et al. (2006) avaliaram o efeito da inoculação de misturas bacterianas em material micropropagado das variedades SP701143 e SP813250 e verificaram resposta positiva sobre a fixação biológica de nitrogênio atmosférico (FBN), com contribuição média de aproximadamente $30 \%$ do nitrogênio acumulado. Esses resultados indicam que a combinação de espécies bacterianas no inoculante é uma estratégia viável para melhorar a FBN e a produtividade da cultura. No Brasil, a produção de inoculante iniciou-se na década de 1950 (Freire, 1968), sendo a turfa o veículo mais utilizado pela indústria até o presente. A turfa é frequentemente importada, já que o país não possui turfa de boa qualidade e por ser um recurso natural pouco frequente (Bucher \& Reis, 2008).

Veículos inoculantes de baixo custo e com potencial para aplicação na agricultura têm sido alvo de intensas pesquisas como, por exemplo, bagaço de cana, serragem, turfa derivada de cacau, casca de arroz, farelo de trigo, carvão vegetal, fosfato de rocha, pó de carvão, lignita, entre outros (Pandey \& Maheshwari, 2007).

Polímeros biodegradáveis têm sido apontados como veículos ecologicamente seguros, por serem degradados pela ação de microrganismos sem causar danos ao meio ambiente. As aplicações tecnológicas desses materiais normalmente requerem melhorias em suas propriedades mecânicas (Rosa et al., 2001). Os polímeros alginato e goma xantana são biodegradáveis, de baixo custo e promovem o encapsulamento das células, liberando-as após a degradação do material no ambiente e protegendo as células contra estresses ambientais; esses polímeros podem, assim, favorecer a multiplicação e sobrevivência das células, quando aplicados ao solo (Denardin \& Freire, 2000; Bashan et al., 2002). Goma arábica, metilcelulose e polivinilpirrolidone (PVP) podem ser usados como adesivos para inoculantes turfosos que contêm células de rizóbio, para auxiliar na cobertura das sementes, proteger as células bacterianas contra a dessecação durante a secagem a vácuo e, assim, aumentar a sobrevivência celular (Deaker et al., 2004; Deaker et al., 2007).

A carboximetilcelulose é um polímero aniônico derivado da celulose, solúvel em água, produzido via reação de Williamson, que ocorre pelo tratamento de celulose com ácido monocloroacético em presença de excesso de hidróxido de sódio. Representa um importante produto industrial, geralmente isolado e comercializado como sal de sódio, com múltiplas possibilidades de aplicação (Fujimoto, 2002). O amido é um carboidrato de estrutura complexa, formado de monossacarídeos ligados entre si e composto por amilose e amilopectina, o que corresponde a 99\% da massa de matéria seca dos grânulos; a razão entre os dois polissacarídeos depende da origem botânica do amido (Tester et al., 2004). É um material natural renovável utilizado em produtos alimentares, papel, têxteis, adesivos, material farmacêutico e na indústria petroquímica (Burgt et al., 1998). A carboximetilcelulose e o amido têm sido utilizados como veículos inoculantes para rizóbio (Rhor, 2007; Fernandes Júnior et al., 2009). Entretanto, são escassas as informações sobre sua aplicação à cana-de-açúcar.

O objetivo deste trabalho foi avaliar o efeito da utilização de inoculantes compostos pela mistura de estirpes de bactérias diazotróficas e pelos polímeros carboximetilcelulose e amido sobre a fixação de nitrogênio, em cana-de-açucar no campo.

\section{Material e Métodos}

Foram utilizadas cinco estirpes de bactérias diazotróficas endofíticas (Tabela 1), previamente testadas e selecionadas por Oliveira et al. (2003) em estudos sobre plântulas micropropagadas de cana-de-açúcar (variedades SP701143 e SP813250), que receberam inoculação de bactérias diazotróficas, em diferentes ambientes de plantio.

Tabela 1. Espécies de bactérias endofíticas e partes da planta de cana-de-açúcar onde as estirpes foram isoladas.

\begin{tabular}{llcc}
\hline Espécies & Estirpe $^{(1)}$ & Partes da planta & Cana-de-açúcar \\
\hline Gluconacetobacter diazotrophicus & BR 11281 & Raízes & Saccharum sp. (híbrido) \\
Herbaspirillum seropedicae & BR 11335 & Raízes & SP701143 \\
Herbaspirillum rubrisubalbicans & BR 11504 & Colmos & SP701284 \\
Azospirillum amazonense & BR 11145 & Colmos & CB453 \\
Burkholderia tropica & BR 11366 & Perfilhos & SP711406 \\
\hline
\end{tabular}

${ }^{(1)}$ Todas as estirpes estão depositadas na coleção de culturas da Embrapa Agrobiologia. 
As estirpes foram cultivadas em tubos de ensaio, sob agitação a $175 \mathrm{rpm}$, a $30^{\circ} \mathrm{C}$ por 24 horas, com os seguintes meios líquidos: LGI-P $+10 \mathrm{mmol} \mathrm{L}^{-1}$ de $\mathrm{NH}_{4} \mathrm{SO}_{4}, \mathrm{pH}$ 5,5 - estirpe BR 11281; JNFb $+1 \mathrm{~g} \mathrm{NH}_{4} \mathrm{Cl}$, pH 5,8 - estirpes BR 11335 e BR 11504; LGI + 1 g de $\mathrm{KNO}_{3}$, pH 6-6,2 estirpe BR 11145; e JMV + $10 \mathrm{mmol} \mathrm{L}^{-1}$ de glutamato de sódio pH 5 - estirpe BR 11366. Foi utilizado $1 \mathrm{~mL}$ das suspensões celulares para a inoculação em $100 \mathrm{~mL}$ de meio líquido NFb modificado (Burdman et al., 1998), com: $5 \mathrm{~g} \mathrm{~L}^{-1}$ de sacarose e pH 6-6,2 - estirpe BR 11145; $100 \mathrm{~g} \mathrm{~L}^{-1}$ de sacarose e $\mathrm{pH} 5,5$ - estirpe BR 11281; $5 \mathrm{~g}$ $\mathrm{L}^{-1}$ de manitol, $\mathrm{pH}$ 5-5,4 - estirpe BR 11366; $5 \mathrm{~g} \mathrm{~L}^{-1}$ de ácido málico, pH 5,8 - estirpes BR 11335 e BR 11504. Foi adicionado $1 \mathrm{~mL}$ de frutose a $0,7 \%(1: 10) \mathrm{em}$ tampão fosfato $0,5 \mathrm{~mol} \mathrm{\textrm {L } ^ { - 1 }}$ esterilizado em filtro Millipore $0,2 \mu \mathrm{m}$. As estirpes foram mantidas a $175 \mathrm{rpm}$, a $30^{\circ} \mathrm{C}$ por 24 horas. Ao final o inoculante foi estocado a $24^{\circ} \mathrm{C}$ pelo período de 15 dias.

Como veículos de inoculante para as bactérias diazotróficas, foram utilizados os polímeros carboximetilcelulose e amido a $60 \%$ e $40 \%(\mathrm{p} / \mathrm{v})$, respectivamente. A partir da proporção 60/40 (CMC/ amido), foram preparadas as misturas poliméricas nas concentrações $0,8 \mathrm{~g} \mathrm{~L}^{-1}$ e 2,2 $\mathrm{g} \mathrm{L}^{-1}$, em água destilada (forma líquida) e na forma gel, respectivamente. Essas misturas poliméricas, cuja formulação está protegida por patente (n- PI0506338-8) no Instituto Nacional de Propriedade Intelectual, receberam a seguinte denominação: IPC 0,8, na forma líquida, e IPC 2,2, na forma de gel. Em seguida, os veículos foram transferidos para sacos de polipropileno com gramatura de aproximadamente $0,05 \mathrm{~mm}$, com $175 \mathrm{~mL}$ ou g de cada veículo e selados. O veículo final foi autoclavado a $120^{\circ} \mathrm{C}$ por $20 \mathrm{~min}$. Posteriormente, cada saco recebeu $75 \mathrm{~mL}$ de suspensão bacteriana com $10^{9}$ células $\mathrm{mL}^{-1}$. $\mathrm{O}$ inoculante foi previamente testado, para atender às normas descritas pelo Ministerio da Agricultura, Pecuária e Abastecimento, para certificação do produto.

Foramutilizados toletes decana-de-açúcardas variedades RB867515 e RB72454, com três gemas previamente selecionadas, que foram tratados termicamente a $52^{\circ} \mathrm{C}$ por $30 \mathrm{~min}$. Em seguida, os toletes foram armazenados em caixas com capacidade para $24 \mathrm{~kg}$, onde permaneceram por 24 horas à temperatura ambiente. Após este período, os toletes foram imersos por $30 \mathrm{~min}$ nos inoculantes líquido (IPC 0,8) e gel (IPC 2,2) diluídos 1:100 em água potável, com cerca de $10^{7}$ células $\mathrm{mL}^{-1}$.
O experimento foi implantado no campo experimental da Embrapa Agrobiologia $\left(22^{\circ} 45^{\prime} \mathrm{S}, 43^{\circ} 40^{\prime} \mathrm{W}\right.$ e $26 \mathrm{~m}$ de altitude), entre setembro de 2007 e agosto de 2008, em Argissolo distrófico de textura média.

As análises de solo, realizadas de acordo com Claessen (1997), indicaram na amostra de 0-20 cm: $\mathrm{pH}$ em água 6,1; $\mathrm{Ca}^{2+}, 3,2 \mathrm{cmol}_{\mathrm{c}} \mathrm{dm}^{-3} ; \mathrm{Mg}^{2+}, 1 \mathrm{cmol}_{\mathrm{c}}$ $\mathrm{dm}^{-3} ; \mathrm{Al}^{3+}, 0,1 \mathrm{cmol}_{\mathrm{c}} \mathrm{dm}^{-3} ; \mathrm{P}, 4,1 \mathrm{mg} \mathrm{dm}^{-3} ; \mathrm{K}, 81 \mathrm{mg}$ $\mathrm{dm}^{-3}, \mathrm{CO}, 0,6 \%$; MO, $1,03 \%$ e N, $0,09 \%$.

$\mathrm{O}$ experimento foi realizado em blocos ao acaso, em esquema fatorial $4 \times 2$ com quatro formas de fornecimento de $\mathrm{N}$ : controle absoluto, controle nitrogênio (adubação com $120 \mathrm{~kg} \mathrm{ha}^{-1}$ de $\mathrm{N}$, inoculante polimérico líquido (IPC 0,8 ), e inoculante polimérico gel (IPC 2,2); e duas variedades de cana-de-açúcar (RB72454 e RB867515), em parcelas subdivididas, com quatro repetições. Cada parcela foi composta de seis linhas de $6 \mathrm{~m}$, com espaçamento de $1,10 \mathrm{~m}$ entre linhas, tendo-se considerado as quatro linhas centrais $\left(26,4 \mathrm{~m}^{2}\right)$ como a área útil de cada parcela. Cada linha da parcela foi considerada como uma subparcela e as subparcelas foram avaliadas aos 6, 9 e 11 meses após o plantio.

O preparo do solo consistiu de uma aração, seguida de gradagem, e a adubação que foi realizada no sulco com superfosfato simples na dose $100 \mathrm{~kg} \mathrm{ha}^{-1}$ de $\mathrm{P}_{2} \mathrm{O}_{5}$, com cloreto de potássio na dose $100 \mathrm{~kg} \mathrm{ha}^{-1}$ de $\mathrm{K}_{2} \mathrm{O}$ e $50 \mathrm{~kg}$ de FTE BR-12, além de $0,4 \mathrm{~kg} \mathrm{ha}^{-1}$ de molibdato de amônio. Foram plantadas 12 gemas de cana por metro linear. No tratamento nitrogênio, foram realizadas duas aplicações em cobertura com $60 \mathrm{~kg} \mathrm{ha}^{-1}$ de $\mathrm{N}$ como ureia, aos 30 e 90 dias após o plantio. $\mathrm{O}$ adubo foi colocado ao lado da linha de plantio e incorporado ao solo.

Durante o corte, a parte aérea das plantas foi separada em colmo, ponteiros (folhas verdes) e palha (folhas secas). Foram avaliados: produtividade de colmos frescos, matéria seca total e acúmulo total de nitrogênio. Amostras de matéria fresca dos ponteiros e da palha foram pesadas no campo, e alíquotas dos componentes da parte aérea foram retiradas, pesadas e levadas à estufa de secagem a $65^{\circ} \mathrm{C}$ até estabilização da massa quando foram novamente pesadas para determinação da matéria seca e N-total, em cada parte da planta. O nitrogênio foi analisado pelo método semimicro Kjeldahl (Alves et al., 1994).

Os resultados obtidos foram submetidos à análise de variância, e as médias foram comparadas pelo teste de Scott-Knott, a 1, 5 e 15\% de probabilidade, e as análises foram realizadas pelos programas SAEG e SISVAR. 


\section{Resultados e Discussão}

Foi observado efeito significativo da aplicação do polímero gel IPC 2,2 e do polímero na forma liquida IPC 0,8 com as bactérias, sobre a produtividade de colmos na variedade RB72454, aos 11 meses após o plantio (Tabela 2), apenas a $15 \%$ de probabilidade. $\mathrm{Na}$ média, o aumento da produtividade de colmos, nesses tratamentos, foi de $50 \mathrm{Mg} \mathrm{ha}^{-1}$ em relação ao controle absoluto, e foi igual ao controle nitrogênio. Para a variedade RB867515, foi observado aumento médio de $30 \mathrm{Mg} \mathrm{ha}^{-1}$ em relação ao controle absoluto, que também não diferiu do controle nitrogênio.

Esses resultados mostram economia na utilização de nitrogênio na cultura, uma vez que apenas a aplicação dos polímeros com a mistura de cinco bactérias diferentes apresentou médias semelhantes de incremento da produtividade de colmos, em comparação ao controle nitrogênio.

Prado Junior (2008), ao testar as variedades de cana RB72454 e IACSP936006, que receberam inoculação de bactérias diazotróficas em condições de campo, observou aumento significativo da produtividade de colmos na variedade RB72454, que recebeu inoculação por pulverização no momento do corte, à linha de plantio, com uma concentração de cerca de $10^{7}$ células $\mathrm{mL}^{-1}$ de Gluconacetobacter diazotrophicus, estirpe BR11281, com produtividade de colmos de $161 \mathrm{Mg} \mathrm{ha}^{-1}$, favorecida tanto pela presença de $\mathrm{N}$ como pela inoculação.
Shankariah \& Hunsigi (2001) observaram aumento da produtividade da cana que recebeu inoculação de Azospirillum brasiliense e Gluconacetobacter diazotrophicus de 9 e de $5 \mathrm{Mg} \mathrm{ha}^{-1}$, respectivamente. Em alguns estudos foi verificada a falta de resposta à inoculação, como observado por Canuto et al. (2003), que mostraram que a resposta à inoculação é bastante variável e parece ser dependente de vários fatores como o genótipo da planta e o ambiente de produção.

Em relação à produção de massa de matéria seca total $($ colmo + ponteiro + palha), não houve diferença significativa entre os tratamentos para a variedade RB72454 (Tabela 3). Para a variedade RB867515, os tratamentos inoculados promoveram aumento significativo, somente a $15 \%$ de probabilidade, de $18 \mathrm{Mg}$ ha ${ }^{-1}$ em relação ao controle absoluto, na produção de massa de matéria seca total, aos 11 meses após o plantio (Tabela 3).

O acúmulo de massa de matéria seca variou entre 62 e $82 \mathrm{Mg} \mathrm{ha}^{-1}$, para a variedade RB72454, e entre 53 e 73 $\mathrm{Mg} \mathrm{ha}^{-1}$, para a variedade RB867515, aos 11 meses após o plantio. A variedade RB72454 obteve produção média de massa de matéria seca total de $73 \mathrm{Mg} \mathrm{ha}^{-1}$, enquanto a RB867515 obteve produção média $67 \mathrm{Mg} \mathrm{ha}^{-1}$, aos 11 meses após o plantio.

Govindarajan et al. (2006), ao avaliar a inoculação de Burkholderia vietnamiensis estirpe MG43, Gluconacetobacter diazotrophicus estirpe ATCC49037, Herbaspirillum seropedicae ATCC35892, e a combinação

Tabela 2. Produtividade de colmos frescos $\left(\mathrm{Mg} \mathrm{ha}^{-1}\right)$ de variedades de cana-de-açúcar, submetidas a quatros tratamentos de fornecimento de nitrogênio, em três épocas de avaliação ${ }^{(1)}$.

\begin{tabular}{|c|c|c|c|}
\hline \multirow[t]{2}{*}{ Tratamento } & \multicolumn{3}{|c|}{ Épocas de avaliação (meses após o plantio) } \\
\hline & 6 & 9 & 11 \\
\hline \multicolumn{4}{|c|}{ Variedade RB72454 } \\
\hline Controle absoluto & $82 \pm 9,83$ & $132 \pm 7,58$ & $123 \pm 2,88 b$ \\
\hline Controle nitrogênio & $100 \pm 7,03$ & $156 \pm 11,31$ & $185 \pm 16,62 \mathrm{a}$ \\
\hline Polímero gel (IPC 2,2) & $85 \pm 2,04$ & $159 \pm 15,92$ & $175 \pm 14,17 \mathrm{a}$ \\
\hline Polímero líquido (IPC 0,8) & $97 \pm 8,88$ & $148 \pm 15,46$ & $171 \pm 26,61 \mathrm{a}$ \\
\hline Média & 91 & 149 & 164 \\
\hline CV parcela $(\%)$ & \multicolumn{3}{|c|}{22,4} \\
\hline CV subparcela (\%) & \multicolumn{3}{|c|}{16,4} \\
\hline \multicolumn{4}{|c|}{ Variedade RB867515 } \\
\hline Controle absoluto & $97 \pm 8,42$ & $154 \pm 14,40$ & $137 \pm 16,02 b$ \\
\hline Controle nitrogênio & $100 \pm 9,84$ & $150 \pm 15,57$ & $172 \pm 6,98 \mathrm{a}$ \\
\hline Polímero gel (IPC 2,2) & $87 \pm 7,34$ & $138 \pm 17,81$ & $173 \pm 7,09 \mathrm{a}$ \\
\hline Polímero líquido (IPC 0,8) & $94 \pm 8,12$ & $150 \pm 8,28$ & $161 \pm 7,40 \mathrm{a}$ \\
\hline Média & 95 & 148 & 161 \\
\hline CV parcela $(\%)$ & & 22,4 & \\
\hline CV subparcela (\%) & & 16,4 & \\
\hline
\end{tabular}

${ }^{(1)}$ Médias \pm erro-padrão seguidas de letras iguais, nas colunas, não diferem entre si pelo teste de Scott-Knott, a $15 \%$ de probabilidade. 
das três, nas variedades Co 86032 e Co 86027 de cana-de-açúcar micropropagada, em diferentes épocas de avaliação até 12 meses após o plantio, verificaram que a inoculação da estirpe MG43 promoveu produção de massa de matéria seca de 191 a $175 \mathrm{Mg} \mathrm{ha}^{-1}$, com aumentos de 20 e 19\%, respectivamente, para as variedades Co 86032 e Co 86027, e foi mais eficiente que as demais estirpes inoculadas.

Estudo realizado por Govindarajan et al. (2007), para avaliar a inoculação das estirpes de Klebsiella sp. GR9 (nova estirpe), Gluconacetobacter diazotrophicus ATCC49037, Herbaspirillum seropedicae ATCC35892, Burkholderia vietnamiensis LMG10929T e Azospirillum lipoferum LMG4348, juntamente com adubação de $140 \mathrm{~kg} \mathrm{ha}^{-1}$ de $\mathrm{N}$ fornecido à cana-de-açúcar micropropagada variedade $\mathrm{CoV}$ 92102, verificaram que tanto a inoculação de Klebsiella sp. GR9 como G. diazotrophicus, associada à adubação de $140 \mathrm{~kg} \mathrm{ha}^{-1}$ de $\mathrm{N}$, promoveu as maiores produções de massa de matéria seca $(3,7$ e 3,1 g por planta, respectivamente), acima do controle fertilizado com $280 \mathrm{~kg} \mathrm{~N} \mathrm{ha}^{-1}$ até seis meses após o plantio.

Quanto ao acúmulo de $\mathrm{N}$ na planta, no presente trabalho, emboranão tenha havido diferença significativa, observou-se, nas duas variedades, um aumento até os 9 meses, com ligeira diminuição aos 11 meses após o plantio (Tabela 4). Essa diminuição no conteúdo de $\mathrm{N}$ na planta pode estar associada ao período de maturação e à proximidade do fim do ciclo da planta. As variedades
RB72454 e RB867515, quando inoculadas com polímeros, apresentaram incremento total de $\mathrm{N}$ nas plantas de cerca de 13 e $20 \%$, respectivamente, em relação ao controle absoluto, aos 11 meses após o plantio, porém sem diferença significativa em relação ao controle e ao controle nitrogênio.

$\mathrm{O}$ acúmulo de $\mathrm{N}$ nas plantas variou entre 263 e $363 \mathrm{~kg} \mathrm{ha}^{-1}$, para a variedade RB72454, e entre 215 e $285 \mathrm{~kg} \mathrm{ha}^{-1}$, para a variedade RB867515, aos 11 meses após o plantio. As duas variedades apresentaram acúmulo médio total de nitrogênio na planta de $306 \mathrm{~kg} \mathrm{ha}^{-1}$, para variedade RB72454, e de $254 \mathrm{~kg} \mathrm{ha}^{-1}$ para variedade RB867515, aos 11 meses após o plantio. Em termos percentuais, a variedade RB72454 apresentou acréscimo de $20 \%$, em relação ao controle absoluto, no acúmulo de nitrogênio na planta.

Contrariamente aos dados do presente trabalho, em estudos realizados por Boddey et al. (2001), Polidoro et al. (2001) e Xavier (2006), quanto à seleção de variedades de cana com potencial para FBN, foi verificado que a variedade RB72454 apresentou resposta significativa no acúmulo de nitrogênio da parte aérea, o que evidenciou o potencial dessa variedade para a FBN em solos pobres em nitrogênio disponível.

Suman et al. (2005), ao avaliar a inoculação individual das estirpes de Gluconacetobacter diazotrophicus IS100, IS107, IS111, IS112, IS113, IS120 e IS121 associada à adubação mineral nitrogenada na dose $75 \mathrm{~kg} \mathrm{ha}^{-1}$ de N em cana-de-açúcar variedade CoSe 92423, verificaram

Tabela 3. Produção de massa de matéria seca total $\left(\mathrm{Mg} \mathrm{ha}^{-1}\right)$ de variedades de cana-de-açúcar, submetidas a quatros tratamentos de fornecimento de nitrogênio, em três épocas de avaliação ${ }^{(1)}$.

\begin{tabular}{lccc}
\hline Tratamento & \multicolumn{3}{c}{ Épocas de avaliação (meses após o plantio) } \\
\cline { 2 - 4 } & 6 & 9 & 11 \\
\hline & & Variedade RB72454 & $62,2 \pm 5,36$ \\
Controle absoluto & $51,0 \pm 5,19$ & $50,1 \pm 3,30$ & $82,2 \pm 8,72$ \\
Pontrole nitrogênio & $59,0 \pm 6,81$ & $49,6 \pm 8,04$ & $73,4 \pm 5,92$ \\
Polímero gel (IPC 2,2) & $60,1 \pm 3,68$ & $63,6 \pm 6,71$ & $75,2 \pm 8,90$ \\
\hline Média & $50,7 \pm 6,33$ & $54,5 \pm 7,56$ & 73,2 \\
CV parcela (\%) & 55,2 & 54,4 & 28,3 \\
CV subparcela (\%) & & 18,5 & $53,0 \pm 12,19 \mathrm{~b}$ \\
\hline & & Variedade RB867515 & $73,7 \pm 2,01 \mathrm{a}$ \\
Controle absoluto & & $47,6 \pm 5,04$ & $68,5 \pm 4,98 \mathrm{a}$ \\
Controle nitrogênio & $5,8)$ & $52,7 \pm 3,11$ & $73,5 \pm 2,64 \mathrm{a}$ \\
Polímero gel (IPC 2,2) & $50,7 \pm 6,92$ & $52,9 \pm 7,50$ & 67,2 \\
Polímero líquido (IPC 0,8) & $54,0 \pm 4,27$ & $52,8 \pm 5,16$ & \\
\hline Média & $56,1 \pm 8,82$ & 51,5 & 18,5 \\
\hline CV parcela (\%) & $56,6 \pm 5,76$ & 54,4 & \\
CV subparcela (\%) & & 28,3 & \\
\hline
\end{tabular}

${ }^{(1)}$ Médias \pm erro-padrão seguidas de letras iguais, nas colunas, não diferem entre si pelo teste de Scott-Knott, a $15 \%$ de probabilidade. 
Tabela 4. Acúmulo total de nitrogênio $\left(\mathrm{kg} \mathrm{ha}^{-1}\right)$ de variedades de cana-de-açúcar, submetidas a quatro tratamentos de fornecimento de nitrogênio, em três épocas de avaliação.

\begin{tabular}{lccc}
\hline Tratamento & \multicolumn{3}{c}{ Épocas de avaliação (meses após o plantio) } \\
\cline { 2 - 3 } & 6 & 9 & 11 \\
\hline Controle absoluto & $236 \pm 32,87$ & Variedade RB72454 & $263 \pm 28,27$ \\
Controle nitrogênio & $298 \pm 25,57$ & $289 \pm 48,88$ & $363 \pm 45,58$ \\
Polímero gel (IPC 2,2) & $244 \pm 15,37$ & $316 \pm 45,12$ & $299 \pm 26,02$ \\
Polímero líquido (IPC 0,8) & $242 \pm 28,08$ & $363 \pm 65,29$ & $298 \pm 47,17$ \\
\hline Média & 255 & $342 \pm 52,06$ & 306 \\
CV parcela (\%) & & 328 & 38,5 \\
CV subparcela (\%) & $205 \pm 53,73$ & 19,4 & $215 \pm 31,87$ \\
& $277 \pm 23,65$ & $284 \pm 52,27$ & $285 \pm 18,64$ \\
Controle absoluto & $229 \pm 34,92$ & $323 \pm 11,90$ & $254 \pm 23,99$ \\
Controle nitrogênio & $239 \pm 27,66$ & $283 \pm 44,81$ & $263 \pm 20,63$ \\
Polímero gel (IPC 2,2) & 238 & $299 \pm 32,33$ & 254 \\
Polímero líquido (IPC 0,8) & 297 & 38,5 \\
\hline Média & & 19,4 & \\
CV parcela (\%) & & \\
CV subparcela (\%) & & \\
\hline
\end{tabular}

que a inoculação de todas as estirpes, exceto a IS121, favoreceu o acúmulo de nitrogênio na parte aérea da planta, com incrementos de 7,32 a 21,97\%, em relação ao controle.

Leite et al. (2008) estudaram o efeito da inoculação da mistura de cinco bactérias sobre o acúmulo de nitrogênio total das variedades RB72454 e RB867515, na região Norte Fluminense, e verificaram que inoculação e reinoculaçãonãopromoveram incrementos significativos no conteúdo total de nitrogênio na parte aérea da plantas. Entretanto, foi verificado que a variedade RB72454 apresentou acúmulo de $124 \mathrm{~kg} \mathrm{ha}^{-1}$ de $\mathrm{N}$, que foi $15 \%$ superior ao da variedade RB867515. Em números absolutos, os autores observaram maior acúmulo de $\mathrm{N}$, quando as variedades RB72454 e RB867515 foram cultivadas com a adubação de $120 \mathrm{~kg} \mathrm{ha}^{-1}$ de $\mathrm{N}$ e com reinoculação dos toletes.

\section{Conclusão}

Em campo, a aplicação de inoculantes, formulados pela mistura de estirpes de bactérias diazotróficas endofíticas e pelos polímeros carboximetilcelulose e amido, promove o aumento da produtividade de colmos e massa de matéria seca da cultura da cana-de-açúcar, aos 11 meses após o plantio.

\section{Agradecimentos}

Ao Conselho Nacional de Desenvolvimento Científico e Tecnológico e ao CT-Agro, pelo apoio financeiro e pela concessão de bolsas; à Fundação Carlos Chagas de Amparo à Pesquisa do Estado do Rio de Janeiro, pela concessão da bolsa "Cientista do nosso Estado".

\section{Referências}

ALVES, B.J.R.; SANTOS, J.C.F. dos; URQUIAGA, S.; BODDEY, R.M. Métodos de determinação do nitrogênio em solo e planta. In: HUNGRIA, M.; ARAUJO, R.S. (Ed.). Manual de métodos empregados em estudo de microbiologia agrícola. Brasília: Embrapa-SPI, 1994. p.449-409. (Embrapa-CNPAF. Documentos, 46).

BASHAN, Y.;HERNANDEZ, J.-P.; LEYVA, L.A.; BACILIO, M. Alginate microbeads as inoculant carriers for plant growth-promoting bacteria. Biology and Fertility of Soils, v.35, p.359-368, 2002.

BODDEY, R.M.; POLIDORO, J.C.; REZENDE, A.S.; ALVES, B.J.R.; URQUIAGA, S. Use of the ${ }^{15} \mathrm{~N}$ natural abundance technique for the quantification of the contribution of $\mathrm{N}_{2}$ fixation to sugar cane and other grasses. Australian Journal of Plant Physiology, v.28, p.889-895, 2001.

BRASIL. Ministério da Agricultura Pecuária e Abastecimento. Balanço nacional da cana-de-açúcar e da agroenergia. Disponível em: <http://www.agricultura.gov.br/>. Acesso em: 17 out. 2008.

BUCHER, C.A.; REIS, V.M. Biofertilizante contendo bactérias diazotróficas. Seropédica: Embrapa Agrobiologia, 2008. 17p. (Embrapa Agrobiologia. Documentos, 247).

BURDMAN, S.; JURKEVITCH, E.; SCHWARTSBURD, B.; HAMPEL, M.M.; OKON, Y. Aggregation in Azospirillum brasilense: effects of chemical and physical factors and involvement of extracellular components. Microbiology, v.144, p.1989-1999, 1998.

BURGT, Y.E.M.van der; BERGSMA, J.; BLEEKER, I.P.; MIJLAND, P.J.H.C.; KERK-VAN HOOF, A. van der; KAMERLING, J.P.; VLIEGENTHART, J.F.G. A distribution of methyl substituents over 
branched and linear regions in methylated starches. Carbohydrate Research, v.312, p.201-208, 1998.

CANUTO, E. de L.; SALLES, J.F.; OLIVEIRA, A.L.M.; PERIN, L.; REIS, V.M.; BALDANI, J.I. Respostas de plantas micropropagadas de cana-de-açúcar à inoculação de bactérias diazotróficas endofíticas. Agronomia, v.37, p.67-72, 2003.

CLAESSEN, M.E.C. (Org.). Manual de métodos de análise de solo. 2.ed. rev. atual. Rio de Janeiro: Embrapa-CNPS, 1997. 212p. (Embrapa-CNPS. Documentos, 1).

DEAKER, R.; ROUGHLEY, R.J.; KENNEDY, I.R. Desiccation tolerance of rhizobia when protected by synthetic polymers. Soil Biology \& Biochemistry, v.39, p.573-580, 2007.

DEAKER, R.; ROUGHLEY, R.J.; KENNEDY, I.R. Legume seed inoculation technology: a review. Soil Biology \& Biochemistry, v.36, p.1275-1288, 2004.

DENARDIN, N.D.; FREIRE, J.R.J. Assessment of polymers for the formulation of legume inoculants. World Journal of Microbiology and Biotechnology, v.16, p.215-217, 2000.

FERNANDES JÚNIOR, P.I.; ROHR, T.G.; OLIVEIRA, P.J. de; XAVIER, G.R.; RUMJANEK, N.G. Polymers as carriers for rhizobial inoculant formulations. Pesquisa Agropecuária Brasileira, v.44, p.1184-1190, 2009.

FREIRE, J.R.J.; RHOR, T.G.; OLIVEIRA, P.J.; XAVIER, G.R.; RUMJANEK, N. G. Trabalhos em rizobiologia no Rio Grande do Sul. In: REUNIÃO LATINO AMERICANA SOBRE INOCULANTES PARA LEGUMINOSAS, 4., 1968, Porto Alegre. Anais. Porto Alegre: Secretaria de Agricultura, 1968. p.19-24.

FUJIMOTO, J. Formação de multicamadas de polissacarídeos e proteína. Química Nova, v.25, p.757-761,2002.

GOVINDARAJAN, M.; BALANDREAU, J.; MUTHUKUMARASAMY, R.; REVATHI, G.; LAKSHMINARASIMHAN, C. Improved yield of micropropagated sugarcane following inoculation by endophytic Burkholderia vietnamiensis. Plant and Soil, v.280, p.239-252, 2006.

GOVINDARAJAN, M.; KWON, S.W.; WEON, H.Y. Isolation, molecular characterization and growth-promoting activities of endophytic sugarcane diazotroph Klebsiella sp. GR9. World Journal of Microbiology and Biotechnology, v.23, p.997-1006, 2007.

INSTITUTO BRASILEIRO DE GEOGRAFIA E ESTATÍSTICA. Levantamento sistemático da produção agrícola. Disponível em: $<$ http://www.ibge.gov.br/home/estatistica/indicadores/agropecuaria/ 1spa/lspa_200902_1.shtm >. Acesso em: 25 mar. 2009.

LEITE, J.M.; MORAIS, R.F.; BARROS, JÚNIOR, J.C.; ALVES, B.J.R.; REIS, V.M.; URQUIAGA, S. Contribuição da fixação biológica de nitrogênio em duas variedades de cana-de-açúcar inoculadas com mistura de bactérias diazotróficas. In: REUNIÃO BRASILEIRA DE FERTILIDADE DO SOLO E NUTRIÇÃO DE PLANTAS, 28.; REUNIÃO BRASILEIRA SOBRE MICORRIZAS,
12.; SIMPÓSIO BRASILEIRO DE MICROBIOLOGIA DO SOLO, 10.; REUNIÃO BRASILEIRA DE BIOLOGIA DO SOLO, 7., 2008, Londrina. Desafios para o uso do solo com eficiência e qualidade ambiental: anais. Londrina: Sociedade Brasileira de Ciência do Solo, 2008. 1 CD ROM.

OLIVEIRA, A.L.M. de; CANUTO, E.D. de; REIS, V.M.; BALDANI, J.I. Response of micropropagated sugarcane varieties to inoculation with endophytic diazotrophic bacteria. Brazilian Journal of Microbiology, v.34, p.59-61, 2003.

OLIVEIRA, A.L.M. de; CANUTO, E.D. de; URQUIAGA, S.; REIS, V.M.; BALDANI, J.I. Yield of micropropagated sugarcane varieties in different soil types following inoculation with diazotrophic bacteria. Plant and Soil, v.284, p.23-32, 2006.

PANDEY, P.; MAHESHWARI, D.K. Bioformulation of Burkholderia sp. MSSP with a multispecies consortium for growth promotion of Cajanus cajan. Canadian Journal of Microbiology, v.53, p.213-222, 2007.

POLIDORO, J.C.; RESENDE, A.S.; QUESADA, D.M.; XAVIER, R.P.; COELHO, C.H.M.; ALVES, B.J.R.; BODDEY, R.M.; URQUIAGA, S. Levantamento da contribuição da fixação biológica de nitrogênio para a cultura da cana-de-açúcar no Brasil. Seropédica: Embrapa Agrobiologia, 2001. 8p. (Embrapa Agrobiologia. Documentos, 144).

PRADO JUNIOR, J.P.Q. Qualidade e produtividade da cana-de-açúcar inoculada com Gluconacetobacter diazotrophicus e adubada com nitrogênio mineral e orgânico. 2008. 49p. Dissertação (Mestrado) - Instituto Agronômico, Campinas.

RHOR, T.G. Estudo reológico da mistura carboximetilcelulose/ amido e sua utilização como veículo de inoculação bacteriano. 2007. 124p. Dissertação (Mestrado) - Universidade Federal Rural do Rio de Janeiro, Seropédica.

ROSA, D.S.; FRANCO, B.L.M.; CALI, M.R. Biodegradabilidade e propriedades mecânicas de novas misturas poliméricas. Polímeros: Ciência e Tecnologia, v.11, p.82-88, 2001.

SHANKARIAH, C.; HUNSIGI, G. Field responses of sugarcane to associative $\mathrm{N}_{2}$ fixers and P solubilisers. In: INTERNATIONAL SOCIETY OF SUGAR CANE TECHNOLOGISTS CONGRESS, 24., 2001, Brisbane. Proceedings. Brisbane: ISSCT, 2001. p.40-45.

SUMAN, A.; GAUR, A.; SHRIVASTAVA, A.K.; YADAV, R.L. Improving sugarcane growth and nutrient uptake by inoculating Gluconacetobacter diazotrophicus. Plant Growth Regulation, v.47, p.155-162, 2005.

TESTER, R.F.; KARKALAS, J.; QI, X. Starch-composition, fine structure and architecture. Journal of Cereal Science, v.39, p.151-165, 2004.

XAVIER, R.P. Contribuição da fixação biológica de nitrogênio na produção sustentável da cultura de cana-de-açúcar. 2006. 71p. Tese (Doutorado) - Universidade Federal Rural do Rio de Janeiro, Seropédica.

$\overline{\text { Recebido em } 29 \text { de abril de } 2009 \text { e aprovado em } 25 \text { de outubro de } 2009}$ 